\title{
Effect of graphene addition on composition, morphology and corrosion behavior of $\mathrm{ZnNiFe}$-graphene composite coatings
}

\author{
Punith Kumar M K ${ }^{1}$, Santanu Ray ${ }^{2}$, Chandan Srivastava ${ }^{1 *}$ \\ ${ }^{1}$ Department of Materials Engineering, Indian Institute of Science, Bangalore, India \\ ${ }^{2}$ School of Environment and Technology, University of Brighton, Brighton, United Kingdom \\ *Corresponding author address: Department of Materials Engineering \\ Indian Institute of Science \\ Bangalore-560012, India \\ Email: csrivastava@iisc.ac.in \\ Phone: 91-80-22932834 \\ FAX: 91-080-2360 0472
}

\begin{abstract}
Graphene reinforced, Zn-rich, Zinc-Nickel-Iron ( $\mathrm{ZnNiFe-G)} \mathrm{coatings} \mathrm{were} \mathrm{deposited} \mathrm{on} \mathrm{mild} \mathrm{steel}$ substrate by electrolyzing the $\mathrm{Zn}-\mathrm{Ni}-\mathrm{Fe}$ acidic sulphate bath containing different amounts of dispersed graphene layers. Effect of graphene incorporation on composition, microstructure, morphology and electrochemical corrosion performance of coatings was investigated. X-ray diffraction studies revealed $\mathrm{ZnNiFe}$ coatings consists $\eta \mathrm{Zn}, \gamma \mathrm{Ni}_{2} \mathrm{Zn}_{11}$ and $\mathrm{Fe}$ phases but the concentration of $\gamma \mathrm{Ni}_{2} \mathrm{Zn}_{11}$ phase increased with increasing graphene content in the coating. Incorporation of graphene enhanced the coating compactness and reduced the micro-pores and surface defects. Presence of graphene increased the $\mathrm{Ni}$ and Fe content in the coatings. The electrochemical corrosion behavior of the composite coatings was determined using potentiodynamic polarization and electrochemical impedance spectroscopy (EIS) techniques. Increase in $\gamma \mathrm{Ni}_{2} \mathrm{Zn}_{11}$ phase concentration, compact and defect free $\mathrm{ZnNiFe}-\mathrm{G}$ composite coatings exhibited $>50 \%$ better corrosion resistance performance when compared to the corrosion resistance exhibited by the graphene free $\mathrm{Zn}-\mathrm{Ni}-\mathrm{Fe}$ coating. Among the $\mathrm{ZnNiFe}-\mathrm{G}$ coatings, the composite coating with combination of highest $\mathrm{Ni}$ and graphene content showed the best corrosion resistance performance.
\end{abstract}


Key words: Graphene; Corrosion; $\mathrm{ZnNiFe}$ Coating.

\section{Introduction}

Zinc coatings are extensively used to protect steel from aggressive environments, however the sacrificial nature of $\mathrm{Zn}$ reduces the life span of the protective $\mathrm{Zn}$ layer [1]. Hence, $\mathrm{Zn}$ alloy coatings, particularly $\mathrm{Zn}-\mathrm{Ni}$ and $\mathrm{Zn}-\mathrm{Fe}$ coatings are largely used for enhanced anti-corrosive performance and high mechanical strength [2-4]. It has been also shown that co-deposition of Fe with $\mathrm{Zn}-\mathrm{Ni}$ alloy to form $\mathrm{ZnNiFe}$ co-deposit further enhances the corrosion resistance, mechanical strength and coating surface uniformity [5-7].

In the case of $\mathrm{Zn}$ alloy electrodeposition, $\mathrm{Zn}$ (even though possessing lower reduction potential) deposits predominantly when compared to other relatively nobler elements like $\mathrm{Ni}$ and Fe. This phenomenon is termed as anomalous co-deposition [5-9]. The anomalous co-deposition is typically observed while co-depositing Fe group elements along with Zn. Several researchers have studied the anomalous deposition behavior and proposed mechanisms such as the hydroxide suppression mechanism (HSM) and underpotential deposition (UPD) of the less noble ions [5-9].

The HSM theory suggests that the inhibition of the nobler metal ion reduction during alloy deposition is caused by the formation of hydroxides of less noble metal at the cathode layer due to the increased $\mathrm{pH}$. On the other hand, the UPD process refers to the deposition of lesser noble metal at a lower reduction potential than the required reduction potential leading to the suppression of the deposition of nobler metal ions. But, still more elucidation of HSM and UPD theories is required to completely understand the anomalous deposition property of $\mathrm{Zn}$ based alloy coatings.

Many researchers have studied the effect of electrolytic bath composition, temperature, $\mathrm{pH}$, effect of organic additives and current density on the anomalous deposition and properties of $\mathrm{Zn}$ Ni-Fe alloy coatings [6, 7, 9-13]. Krisha et al [10] have studied the anomalous behavior during 
electrodeposition of $\mathrm{ZnNiFe}$ at different $\mathrm{pH}$ and current densities on low carbon steel substrate. They have argued that during the electrodeposition process, Ni and Fe ions or the monovalent intermediates of $\mathrm{Ni} / \mathrm{Fe}$ ions precedingly get adsorbed on the cathode followed by the adsorption of zinc ion or its monovalent intermediates onto the freshly adsorbed/deposited $\mathrm{Ni}$ and $\mathrm{Fe}$ ions. The adsorbed $\mathrm{Zn}$ ions on the $\mathrm{Ni}$ and $\mathrm{Fe}$ layer inhibits the subsequent deposition of $\mathrm{Ni}$ and $\mathrm{Fe}$. This happens due to the competitive adsorption between $\mathrm{Zn}, \mathrm{Ni}$ and $\mathrm{Fe}$ and their monovalent intermediates. This competition on occupying the cathodic active sites leads to the preferential deposition of $\mathrm{Zn}$, although $\mathrm{Zn}$ does not block the deposition of Ni and Fe completely [10]. Hegde et al [12] have reported on the effect of organic additives in enhancing the concentration of $\mathrm{Ni}$ and $\mathrm{Fe}$ in $\mathrm{Zn}-\mathrm{Ni}-\mathrm{Fe}$ co-deposition, they have also reported that the addition of organic additive enhances the corrosion resistance property of the $\mathrm{ZnNiFe}$ ternary alloy [12]. Oliveira et al [13] increased the concentration of $\gamma \mathrm{Ni}_{2} \mathrm{Zn}_{11}$ intermetallic phase by increasing the $\mathrm{Fe}^{2+}$ ion concentration in the $\mathrm{ZnNiFe}$ plating bath and also observed refined microstructure and morphology for $\mathrm{ZnNiFe}$ deposit upon using ascorbic acid as organic additive [13].

Graphene, a carbon allotrope is used in sensors, automobiles and energy storage devices because of its notable electrical, thermal and mechanical properties [14-17]. However, graphene and graphene oxide are used to incorporate with organic coatings and metal matrix composite coatings to protect the substrate materials from corrosion process [18-25]. Recently, researchers have illustrated that the incorporation of graphene into the growing metal matrix coatings induces noticeable changes in the coating morphology and microstructure yielding significantly better anticorrosive property of the coatings [18]. Also, our previous study illustrates that the incorporation of graphene alters the microstructure, morphology and compactness of the Zn-Fe alloy coating resulting in improved corrosion resistance performance [19]. 
Effect of graphene incorporation on the composition, microstructure, morphology and electrochemical performance of $\mathrm{ZnNiFe}$ deposits is yet unexplored, hence the present study is focused on this. Zn-rich, ZnNiFe-graphene composite coatings were electrolytically deposited on mild steel surface. The incorporation of graphene significantly altered the coating surface morphology and enhanced the concentration of $\mathrm{Ni}$ in the coating leading to enhanced corrosion resistance property of the $\mathrm{ZnNiFe}-\mathrm{G}$ composite coating.

\section{Experimental}

All the chemicals used in the current work were purchased from Sd fines India and were used as received.

\subsection{Electrodeposition of $\mathrm{Zn}-\mathrm{Ni}-\mathrm{Fe}$ and $\mathrm{Zn}-\mathrm{Ni}-\mathrm{Fe}$-G composite coatings}

Graphene was synthesized by the electrochemical exfoliation of graphite in $0.5 \mathrm{M}$ Sodium lauryl sulphate electroactive media using CHI 604E electrochemical workstation by applying 5V through chronoamperometry technique. Detailed discussion on the synthesis process is provided in our previous article [19].

Electrodeposition of $\mathrm{Zn}-\mathrm{Ni}-\mathrm{Fe}$ and $\mathrm{Zn}-\mathrm{Ni}-\mathrm{Fe}-\mathrm{G}$ coatings were performed using the electrolytic bath composition and deposition parameters given in the Table 1. Zn-Ni-Fe-G coatings were obtained by dispersing different amounts of graphene into the electrolyte followed by $15 \mathrm{~min}$ ultrasonication in order to uniformly disperse the graphene in the electrolytic bath solution. The electrolytic baths used for the deposition process were named as $\mathrm{B}_{0}(\mathrm{Zn}-\mathrm{Ni}-\mathrm{Fe}+0 \mathrm{mg} / \mathrm{l}$ of Graphene), $\mathrm{B}_{1}$ (Zn-Ni-Fe+10 mg /l of Graphene), $\mathrm{B}_{2}$ (Zn-Ni-Fe+25 mg /l of Graphene), B (Zn$\mathrm{Ni}-\mathrm{Fe}+50 \mathrm{mg} / \mathrm{l}$ of Graphene) and $\mathrm{B}_{4}$ (Zn-Ni-Fe+75 mg /l of Graphene). Mild steel plate of $20 \mathrm{~mm}$ x $40 \mathrm{~mm}$ area with $1 \mathrm{~mm}$ thickness was used as cathode and platinum plate was used anode. Mild steel plates were polished using different grit emery papers (400-2500) then were degreased and 
cleaned by dipping in dil. $\mathrm{HCl}$ and dil. $\mathrm{NaOH}$ followed by water wash. The anode was also degreased and cleaned using dil. $\mathrm{HCl}$ and dil. $\mathrm{NaOH}$ solutions. Coatings were obtained by applying $10 \mathrm{~mA} / \mathrm{cm}^{2}$ current density for 45 minutes at $43 \pm 2{ }^{\circ} \mathrm{C}$ temperature. Obtained coatings were named as $\mathrm{G}_{0}(\mathrm{ZnNiFe}+0 \mathrm{mg} / \mathrm{l}$ of Graphene $), \mathrm{G}_{10}(\mathrm{ZnNiFe}+10 \mathrm{mg} / \mathrm{l}$ of Graphene $), \mathrm{G}_{25}$ $(\mathrm{ZnNiFe}+25 \mathrm{mg} / \mathrm{l}$ of Graphene $), \mathrm{G}_{50}(\mathrm{ZnNiFe}+50 \mathrm{mg} / \mathrm{l}$ of Graphene $)$ and $\mathrm{G}_{75}(\mathrm{ZnNiFe}+75 \mathrm{mg} / \mathrm{l}$ of Graphene).

\subsection{Characterization}

Zeta potential/surface charge of the dispersed graphene in $\mathrm{ZnNiFe}$ plating electrolyte was measured using Malvern zeta potential analyzer and the agglomeration state of the graphene in the electrolyte was analyzed by dynamic laser light scattering method by means of particle size distribution (PSD) analysis. Surface morphology and composition of the coatings were analyzed using ESEM Quanta-200 Scanning electron microscope (SEM) coupled with energy dispersive Xray spectroscopy (EDS) detector. The X-ray diffraction (XRD) analysis of the $\mathrm{ZnNiFe}$ and ZnNiFe-G coatings was performed using PANalytical JDX-8030 diffractometer employing a Cu $\mathrm{K} \alpha$ radiation $(\lambda=0.1540 \mathrm{~nm})$ source.

Cathodic polarization curves for the $\mathrm{ZnNiFe}$ and $\mathrm{ZnNiFe}-\mathrm{G}$ electrolyte were recorded using CHI 604E electrochemical workstation with mild steel cathode of $0.23 \mathrm{~cm}^{2}$ area, $1 \mathrm{M} \mathrm{Ag} / \mathrm{AgCl}$ electrode as reference and platinum plate as counter electrode respectively. CHI 604E electrochemical workstation with three electrode system of single compartment glass cell was used for the electrochemical corrosion analysis of the coatings. The $\mathrm{ZnNiFe} / \mathrm{ZnNiFe}-\mathrm{G}$ deposited steel plate with $1 \mathrm{~cm}^{2}$ exposed area was used as the working electrode. $1 \mathrm{M} \mathrm{Ag} / \mathrm{AgCl}$ and platinum plate were used as reference and counter electrode respectively. $3.5 \mathrm{wt} \% \mathrm{NaCl}$ solution was used as corrosive media and all the electrochemical measurements were carried out at room temperature. 
The electrochemical measurement setup with working electrode in contact with the corrosive media was kept for 60 mins in order to obtain the equilibrium state, meanwhile the open circuit potential (OCP) of the respective working electrode was obtained. The potentiodynamic polarization measurements were carried out by polarizing the working electrode from its corresponding OCP to $\pm 200 \mathrm{mV}$. The electrochemical corrosion parameters like corrosion potential $\left(\mathrm{E}_{\text {corr }}\right)$, corrosion current $\left(\mathrm{I}_{\mathrm{corr}}\right)$ and corrosion rate $(\mathrm{CR})$ were obtained from the polarization curves. Coating resistance was examined by electrochemical impedance spectroscopy (EIS) at the OCP of the corresponding coating by applying sinusoidal signal with AC frequency range from $100 \mathrm{kHz}$ to $100 \mathrm{mHz}$ at 6 points per decade. Obtained EIS data was curve fitted using ZSimpWin 3.21 to obtain the corrosion parameters. All the experiments were repeated to confirm the reproducibility of the results.

\section{Results and Discussion}

Details on the electrochemical exfoliation of graphene and the characterization of exfoliated graphene is provided in our previous article [19]. The graphene layers, produced from the electrochemical exfoliation technique, were dispersed in $\mathrm{ZnNiFe}$ electroplating bath in different amount (as given in Table 1) to produce the $\mathrm{ZnNiFe-G}$ coatings on mild steel substrate.

\subsection{Zeta potential and particle size distribution analysis}

The solid particles possess electrical charge when they come in contact with electrolyte interface and under a applied electric field, the particles then move towards positive or negative electrode based on the charge on the particle surface i.e., surface charge/zeta potential. In the present case, surface charge/zeta potential of graphene dispersed in the $\mathrm{B}_{1}, \mathrm{~B}_{2}, \mathrm{~B}_{3}$ and $\mathrm{B}_{4}$ plating bath was measured to be $+9.08 \mathrm{mV},+9.54 \mathrm{mV},+9.51 \mathrm{mV}$ and $+8.47 \mathrm{mV}$ respectively. The positive charge indicated that the dispersed graphene layers moved towards the cathode surface 
along with metal ion cloud resulting in the incorporation of graphene into the $\mathrm{ZnNiFe}$ coating matrix. The average graphene agglomerate size in the plating bath solution was analyzed via dynamic light scattering method. The measured average agglomerate size of graphene in the $\mathrm{B}_{1}$, $\mathrm{B}_{2}, \mathrm{~B}_{3}$ and $\mathrm{B}_{4}$ plating bath was $2061 \mathrm{~nm}, 3278 \mathrm{~nm}, 4339 \mathrm{~nm}$ and $5545 \mathrm{~nm}$ respectively. Graphene agglomeration increased with increasing graphene concentration in the plating electrolyte.

\subsection{Characterization of coatings: microstructure, morphology and composition analysis}

The $\mathrm{ZnNiFe}$ and $\mathrm{ZnNiFe-G}$ coatings were prepared using the plating bath composition and deposition parameters given in Table 1. Representative SEM micrographs of the $\mathrm{ZnNiFe}$ and ZnNiFe-G coatings are shown in Fig. 1(a). It can be observed from Fig. 1(a) that the ZnNiFe coating has non-compact globular morphology with pores or defects on the surface (highlighted by the white arrow). It can be further observed in the Fig. $1\left(\mathrm{G}_{10}-\mathrm{G}_{75}\right)$ that incorporation of graphene into the growing $\mathrm{ZnNiFe}$ matrix altered the coating morphology. Relatively compact and defect free surface morphology was obtained for the $\mathrm{ZnNiFe}-\mathrm{G}$ coatings. Between the composite coatings, high coating compactness can be observed for $\mathrm{G}_{10}, \mathrm{G}_{25}$ and $\mathrm{G}_{50}$ coatings. $\mathrm{G}_{25}$ and $\mathrm{G}_{50}$ coating contained nearly spherical hillock structures. These hillock structures were made up of very fine $\mathrm{Zn}$ fibers as reveled by the Fig. 1(a). Formation of such hillock structures has been earlier reported in case of $\mathrm{Zn}$-graphene composite coatings [26]. Whereas, $\mathrm{G}_{75}$ coating exhibits relatively lesser compactness and noticeable surface defects (denoted by the white arrow). This may due to the non-uniform distribution of agglomerated graphene layers in the $G_{75}$ coating microstructure during the electrodeposition process.

Elemental composition of the coatings is provided in the Table 2. Incorporation of graphene in the $\mathrm{ZnNiFe}$ coating was confirmed by the carbon content of the composite coatings determined by the EDS analysis. Increase in the graphene amount in the electrolyte led to a 
corresponding enhancement in the carbon weight percent in the coatings from $G_{10}$ to $G_{25}$. However, for $\mathrm{G}_{50}$ and $\mathrm{G}_{75}$ coatings the carbon content decreased even though they were produced from electrolyte bath with higher amount of graphene. This is possibly due to the agglomeration (as evident from the particle size analysis results) and sedimentation of the graphene sheets in the electrolyte. Representative SEM micrographs showing partially embedded graphene sheets in the composite coatings is provided in Fig. 1(b).

In the present study, as observed in the literature, anomalous deposition behavior was noticed in the case of pristine $\mathrm{ZnFeNi}$ coatings resulting in dominant deposition of $\mathrm{Zn}$. The composition of $\mathrm{ZnNiFe}$ deposit was measured as $1.23 \mathrm{wt} \%$ of Fe, $3.54 \mathrm{wt} \%$ of $\mathrm{Ni}$ and $95.22 \mathrm{wt} \%$ of $\mathrm{Zn}$. Incorporation of graphene into the growing $\mathrm{ZnNiFe}$ matrix, however, significantly influenced the overall composition. The Fe content in the coating increased from $1.23 \mathrm{wt} \%$ to 2 wt $\%$ and the Ni content increased from $3.54 \mathrm{wt} \%$ to approximately $5-6 \mathrm{wt} \%$. The highest amount (6.54 wt\%) of $\mathrm{Ni}$ was observed for the $\mathrm{G}_{25}$ sample which also contained highest amount of graphene $(3.45 \mathrm{wt} \% \mathrm{C})$. This result revealed that, overcoming the anomalous deposition condition, the incorporation of graphene into $\mathrm{ZnNiFe}$ matrix enhances nobler metal content in the ternary deposit.

Vathsala et al [27] studied the effect of $\mathrm{MoS}_{2}$ nanoparticles on the $\mathrm{Zn}$ deposition process and observed a shift in $\mathrm{Zn}$ deposition potential for the $\mathrm{Zn}-\mathrm{MoS}_{2}$ coatings because of cathodic polarization caused by the $\mathrm{MoS}_{2}$ particles [27]. In the current work, to know the effect of graphene on the deposition process cathodic polarization experiments were carried out for the electrolytic bath solution $\mathrm{B}_{0}$ and $\mathrm{B}_{25}$ and the recorded cathodic polarization curves are given in Fig. 2. The cathodic polarization curves were measured from $-0.4 \mathrm{~V}$ to $-1.2 \mathrm{~V}$. As observed in Fig. 2, massive deposition of $\mathrm{Zn}$ from the plating bath $\mathrm{B}_{0}$ is initiated at around $0.97 \mathrm{~V}$ with visible reduction peak 
$\mathrm{R}_{1}$ followed by hydrogen evolution. Addition of graphene into the electrolytic bath, however, shifts the deposition peak potential considerably to more negative value and the deposition now starts around $1.01 \mathrm{~V}$ for the $\mathrm{B}_{25}$ plating bath and the reduction peak $\mathrm{R}_{1}$ is more prominent with increased current density. This result revealed that the adsorption of graphene layers on the cathode active sites polarized the deposition potential of $\mathrm{Zn}$ and affected the UPD of Zn slightly delayed the $\mathrm{Zn}$ deposition, hence increasing the amount of $\mathrm{Ni}$ and Fe content in the deposit.

X-ray diffraction profiles of the $\mathrm{ZnNiFe}$ and $\mathrm{ZnNiFe}-\mathrm{G}$ coatings are given in Fig. 3(a,b). Fig. 3(a) shows peak in the 2-theta range of 35-50 and Fig. 3(b) shows peak in the 2-theta range of 50-90. All the coatings contained $\eta$ phase (a solid solution of $\mathrm{Ni}$ in $\mathrm{Zn}$ ), $\gamma$ phase of cubic $\mathrm{Ni}_{2} \mathrm{Zn}_{11}$ intermetallic and pure Fe peaks [9]. It can be clearly observed that, the relative intensity of peak (with respect to the $\eta$ phase peak) corresponding to the $\gamma \mathrm{Ni}_{2} \mathrm{Zn}_{11}$ intermetallic phase and Fe phase increased for graphene reinforced $\mathrm{ZnNiFe}$ coatings compared to the graphene free $\mathrm{ZnNiFe}$ coating. This indicates that $\gamma \mathrm{Ni}_{2} \mathrm{Zn}_{11}$ intermetallic concentration (or $\mathrm{Ni}$ concentration which is required to form this phase) and Fe concentration increased in the coatings after the incorporation of graphene. Average grain size of the different phases in the coating calculated using the Scherrer formula [28] is given in the Table 3. Incorporation graphene did not produce any noticeable change in the grain sizes of the phases in the coating microstructure.

\subsection{Electrochemical corrosion analysis}

The electrochemical corrosion performance of the $\mathrm{ZnNiFe}$ coatings with and without graphene was determined using the potentiodynamic polarization and electrochemical impedance analysis. The Tafel polarization curves were measured in $3.5 \mathrm{wt} \% \mathrm{NaCl}$ corrosive media at room temperature using three electrode system where $1 \mathrm{M} \mathrm{Ag} / \mathrm{AgCl}$ and platinum plate served as reference and counter electrode respectively. The $\mathrm{ZnNiFe}$ and $\mathrm{ZnNiFe}-\mathrm{G}$ coatings of $1 \mathrm{~cm}^{2}$ area 
exposed to the electroactive media was used as working electrode. The working electrode was polarized to $\pm 200 \mathrm{mV}$ from the respective open circuit potential to obtain the Tafel polarization curves given in Fig. 4. Table 4 provides the values of the corrosion parameters: corrosion potential ( $\left.E_{\text {corr }}\right)$, corrosion current $\left(\mathrm{I}_{\mathrm{corr}}\right)$, corrosion rate $(\mathrm{CR})$, cathodic slope $\left(\beta_{\mathrm{c}}\right)$ and anodic slope $\left(\beta_{\mathrm{a}}\right)$ obtained from the analysis of the Tafel curves. The $\mathrm{E}_{\mathrm{corr}}$ of graphene reinforced $\mathrm{ZnNiFe}$ coatings was more positive than the $\mathrm{E}_{\mathrm{corr}}$ of pure $\mathrm{ZnNiFe}$ coatings which illustrates that more energy is required to corrode the $\mathrm{ZnNiFe}-\mathrm{G}$ coatings. Among the $\mathrm{ZnNiFe}-\mathrm{G}$ composite coatings, the $\mathrm{G}_{25}$ coating exhibited better corrosion potential when compared to $\mathrm{G}_{10}, \mathrm{G}_{50}$ and $\mathrm{G}_{75}$ coatings. The corrosion current value obtained for $\mathrm{G}_{0}, \mathrm{G}_{10}, \mathrm{G}_{25}, \mathrm{G}_{50}$ and $\mathrm{G}_{75}$ coatings respectively were 9.359 $\mu \mathrm{A} / \mathrm{cm}^{2}, 4.274 \mu \mathrm{A} / \mathrm{cm}^{2}, 2.504 \mu \mathrm{A} / \mathrm{cm}^{2}, 3.957 \mu \mathrm{A} / \mathrm{cm}^{2}$ and $4.134 \mu \mathrm{A} / \mathrm{cm}^{2}$. Lower the corrosion current value, better is the corrosion resistance of the coating. It can be observed that all the $\mathrm{ZnNiFe}-\mathrm{G}$ coatings exhibit higher corrosion resistance property when compared to $\mathrm{ZnNiFe}$ coating. The best among them, the $\mathrm{G}_{25}$ coating yields $\sim 75 \%$ reduced corrosion current compared to $\mathrm{G}_{0}$ coating. The accelerated corrosion behavior of the graphene free $\mathrm{G}_{0}$ coating is due to the pores and defects present in the coating as noticed in the SEM micrograph of $\mathrm{G}_{0}$ coating in Fig. $1\left(\mathrm{G}_{0}\right)$. The micro-pores or defects act like active sites during the corrosion process facilitating higher corrosion current and diminished corrosion resistance. The defect free compact surface, presence of chemically inert and impermeable graphene layer and increased concentration of $\mathrm{Ni}$ in the $\mathrm{ZnNiFe}-\mathrm{G}$ composite coatings imparted better corrosion resistance to the composite coating when compared to the $\mathrm{ZnNiFe}$ coatings. The coating with highest amount of graphene and $\mathrm{Ni}$ content in it i.e., $\mathrm{G}_{25}$ coating showed the best corrosion resistance property among the graphene reinforced $\mathrm{ZnNiFe}$ coatings. Among the composite coatings, $\mathrm{G}_{75}$ coating showed least corrosion 
resistance behavior, which may be due to the defects arising from the non-uniform distribution of agglomerated graphene in the coating matrix.

The electrochemical impedance measurements were performed at the OCP value of the respective working electrode by applying the signal in the frequency range from $100 \mathrm{kHz}$ to 100 $\mathrm{mHz}$ with sinusoidal signal amplitude of 5V. EIS data were recorded at 6 points per decade. The measured EIS data is presented as typical Nyquist plot in Fig. 5(a) and log frequency Vs $\log |\mathrm{Z}|$ \& phase angle Bode plots in Fig. 5(b). In the Nyquist plot, difference between the high and low frequency end of the capacitive loop on the impedance real axis reveals the corrosion resistance property of the material. The curve corresponding to the $\mathrm{G}_{25}$ coating exhibits the largest loop illustrating that the $\mathrm{G}_{25}$ coating has highest resistance towards the corrosive media. However, all the $\mathrm{ZnNiFe}-\mathrm{G}$ coatings showed better corrosion resistance than the graphene free $\mathrm{ZnNiFe}$ coating, same can be observed in $\log |\mathrm{Z}| \mathrm{v} / \mathrm{s} \log$ frequency Bode plot. In the phase angle v/s log frequency graph, the phase angle corresponding to all the coatings at high frequency range is around zero, this suggests that all the coatings are resistive in nature [29].

Two capacitive loops or two-time constants are observed in Nyquist plot for all the coatings and this behavior is well resolved in the phase angle v/s log frequency Bode plot. Therefore, the EIS data were fitted with suitable $2 \mathrm{RC}$ electrical equivalent circuit (EEC, Fig. 6) to understand the corrosion process occurring at the electrode/electrolyte interface. The low frequency capacitance element in the used EEC was replaced with a constant phase element (CPE, Q) for the better fitting results. The following equation defines the impedance of the $\mathrm{CPE}$

$$
Z(j \omega)=(Q)^{-1}(j \omega)^{-n}
$$

In the above equation, ' $Q$ ' is $\mathrm{CPE}$ constant with angular frequency ' $\omega$ ' where $\omega=2 \pi f$ (' $f$ ' is the frequency), $j$ is the imaginary unit and ' $n$ ' is the CPE exponent $(-1 \leq n \leq 1)$. The ' $n$ ' value 
represents the charge distribution on the surface. The ' $n$ ' value for ideal capacitor is 1 and it decreases with increased surface roughness because of the non-uniform distribution of current on the surface [30].

In the given EEC (Fig. 6), $\mathrm{R}_{\mathrm{S}}$ represents the solution resistance, the high frequency RC couple $C_{d}-R_{d}$ are related to the dielectric character $\left(C_{d}\right)$ of the coating that is reinforced by ionic conduction through its pores $\left(\mathrm{R}_{\mathrm{d}}\right)$. The low frequency $\mathrm{RC}$ couple $\mathrm{R}_{\mathrm{ct}}-\mathrm{Q}_{\mathrm{dl}}$ represents the charge transfer resistance and the double layer capacitance [31].

The electrochemical corrosion parameters obtained from EEC curve fitting are given in Table 5. The polarization resistance $R_{p}$ i.e., $R_{p}=R_{d}+R_{c t}$ value is directly proportional to the anticorrosive property of the coating. The graphene reinforced $\mathrm{ZnNiFe}$ coatings showed higher polarization resistance than the graphene free $\mathrm{ZnNiFe}$ coating. The corrosion resistance of the $\mathrm{G}_{0}$ coating was minimum compared to all other coatings because of the accelerated corrosion process occurring at the surface defects. Also, the double layer capacitance $\mathrm{Q}_{\mathrm{dl}}$ value for coating $\mathrm{G}_{0}$ was very high when compare to $\mathrm{ZnNiFe}-\mathrm{G}$ coatings because of considerable corrosion products formation on the $\mathrm{G}_{0}$ surface. Also, the decreased CPE exponent ' $n$ ' value for $\mathrm{G}_{0}$ coating suggest that the surface is non-uniform in nature because of the surface defects. Even for the Graphene reinforced $\mathrm{ZnNiFe}$ coatings, the observed ' $\mathrm{n}$ ' value was around 0.75 which may be due to the surface unevenness caused from the formed hillock structures on the composite coatings surface (Fig. 1(a)), however, the composite coatings possessed better corrosion resistance because of the relatively more compact and defect free nature of the coating. The Graphene reinforced $\mathrm{ZnNiFe}$ coatings were found to be less active towards the external aggressive media and these coatings are offer considerably high resistance for the charge transfer. Hence, the active charge collection on the graphene embedded coating surface is minimum, therefore double layer capacitance value for 
graphene incorporated $\mathrm{ZnNiFe}$ composite coatings is significantly decreased. Among all the composite coatings, $\mathrm{G}_{25}$ coating obtained from the electrolytic bath loaded with $25 \mathrm{mg} / \mathrm{l}$ showed best corrosion resistance property by exhibiting increased charge transfer resistance $\mathrm{R}_{\mathrm{ct}}$ with least double layer capacitance value.

The $\mathrm{ZnNiFe}$ coatings mainly consist of $\eta \mathrm{Zn}, \gamma \mathrm{Ni}_{2} \mathrm{Zn}_{11}$ and $\mathrm{Fe}$ phases and dezincification occurs from $\eta \mathrm{Zn}, \gamma \mathrm{Ni}_{2} \mathrm{Zn}_{11}$ and the dissolution rate of $\mathrm{Zn}$ from $\gamma \mathrm{Ni}_{2} \mathrm{Zn}_{11}$ phase is significantly lower [9]. In the present study, the Ni content in the alloy coating increased with increase in carbon content and it may enhance the $\gamma \mathrm{Ni}_{2} \mathrm{Zn}_{11}$ phase concentration in the $\mathrm{ZnNiFe}$ alloy coating. The increased $\gamma \mathrm{Ni}_{2} \mathrm{Zn}_{11}$ phase concentration in the graphene incorporated coatings offered more resistance to zinc dissolution process [9]. Also, change in microstructure and morphology of the ZnNiFe-G coatings due to incorporation of graphene significantly improves the corrosion resistance property of the $\mathrm{ZnNiFe}-\mathrm{G}$ coatings compared to graphene free $\mathrm{ZnNiFe}$ coating. The electrochemical corrosion properties of $\mathrm{ZnNiFe}$ and $\mathrm{ZnNiFe}-\mathrm{G}$ coatings compliments with the observed surface morphology and graphene content of the respective coatings. The $\mathrm{ZnNiFe}$ coating obtained without adding graphene possessed micro pores and defects in the coatings hence it showed degraded corrosion resistance property. Whereas, the graphene reinforced $\mathrm{ZnNiFe}$ coatings exhibited better anticorrosion resistance property because of the compact and defect free morphology. Among the composite coatings, the $\mathrm{G}_{25}$ coating obtained from the plating bath loaded with $25 \mathrm{mg} / \mathrm{l}$ of graphene displayed superior corrosion resistance property. The $\mathrm{G}_{75}$ coating exhibited lesser corrosion resistance than $\mathrm{G}_{25}$ and $\mathrm{G}_{50}$, which may due to the defects formed from the non-uniform distribution of agglomerated graphene in the coating microstructure.

\section{Conclusion:}


$\mathrm{ZnNiFe}$ and graphene reinforced $\mathrm{ZnNiFe}$ coatings were electrodeposited over mild steel substrate. Graphene was synthesized by electrochemical exfoliation technique. ZnNiFe coating obtained without adding graphene possessed micro pores and defects on the surface. Incorporation of graphene, however, enhanced the coating compactness and removed the micro-pores and defects in the coating morphology. Incorporation of graphene to the $\mathrm{ZnNiFe}$ coating influenced the anomalous deposition behaviour of $\mathrm{Zn}$ and facilitated uptake and higher concentration of $\mathrm{Ni}$ and $\mathrm{Fe}$ in the $\mathrm{ZnNiFe}-\mathrm{G}$ coatings. Potentiodynamic polarization and EIS based investigations of the coatings revealed that the addition of graphene enhanced the corrosion resistance behaviour of the $\mathrm{ZnNiFe}$ coatings. Between the composite coatings, the coating with highest amount of graphene and $\mathrm{Ni}$ content yielded the best corrosion resistance performance.

\section{Acknowledgement}

The authors acknowledge the research funding received form the Ministry of Mines and CSIR Government of India.

\section{References:}

[1] B. M. Praveen, T. V. Venkatesha, Y. A. Naik, K. Prashantha, Corrosion studies of carbon nanotubes-Zn composite coating, Surf. Coat. Technol. 201 (2007) 5836-5842.

[2] I. Suzuki, M. Enjuzi, The development of the corrosion resistance of an Fe-Zn alloy coating on the basis of the behavior of the corrosion product, Corros. Sci. 26 (1986) 349-355.

[3] N. Eliaz, K. Venkatakrishna, A. C. Hegde, Electroplating and characterization of Zn-Ni, ZnCo and Zn-Ni-Co alloys, Surf. Coat. Technol. 05 (2010) 1969-1978.

[4] B. M. Praveen, T. V. Venkatesha, Electrodeposition and properties of $\mathrm{Zn}-\mathrm{Ni}-\mathrm{CNT}$ composite Coatings, J. Alloys Compd. 482 (2009) 53-57.

[5] M. M. Younan, O. A. Fadali, I. H. M. Aly, T. Oki, Polarization phenomenon during Zn-Ni-Fe alloy electrodeposition in acidic chloride bath, Mater. Trans. 37 (1996) 1763-1767.

[6] M. M. Younan, T. Oki, Electrodeposition of Zn-Ni-Fe alloy in acidic chloride bath with separated Anodes, J. Appl. Electrochem. 26 (1996) 537-541.

[7] M. M. Abou-Krisha, F. H. Assaf, S. A. El-Naby, Electrodeposition and characterization of 
zinc-nickel-iron alloy from sulfate bath: influence of plating bath temperature, J. Solid State Electrochem. 13 (2009) 879-885.

[8] A. Brenner, Electrodeposition of Alloys. Principle and Practice, Academic Press, New York and London, 1963.

[9] M. M. Abou-Krisha, F. H. Assaf, S. A. El-Naby, Electrodeposition behavior of zinc-nickeliron alloys from sulfate bath, J. Coat. Technol. Res. 6 (2009) 391-399.

[10] M. M. Abou-Krisha, Effect of $\mathrm{pH}$ and current density on the electrodeposition of $\mathrm{Zn}-\mathrm{Ni}-\mathrm{Fe}$ alloys from a sulfate bath, J. Appl. Electrochem. 9 (2012) 775-783.

[11] M. Ebadia, W. J. Basirun, Y. Alias, M. R. Mahmoudian, S. Y. Leng, Investigation of electrodeposition of $\mathrm{Ni}-\mathrm{Co}-\mathrm{Fe}-\mathrm{Zn}$ alloys in DMSO with MHD effect, Mater. Charact. 66 (2012) 46-55.

[12] A. C. Hegde, K. Venkatakrishna, N. Eliaz, Electrodeposition of $\mathrm{Zn}-\mathrm{Ni}, \mathrm{Zn}-\mathrm{Fe}$ and $\mathrm{Zn}-\mathrm{Ni}-$ Fe Alloys, Surf. Coat. Technol. 205 (2010) 20312041.

[13] R. P. Oliveira, D. C. Bertagnolli, E. A. Ferreira, L. da Silva, A. S. Paul, Influence of $\mathrm{Fe}^{2+}$ oxidation and its antioxidant ascorbic acid as additive in $\mathrm{Zn}-\mathrm{Ni}-\mathrm{Fe}$ electrodeposition process on a low carbon steel, Surf. Coat. Technol. 349 (2018) 874-884.

[14] S. Sato, Graphene for nanoelectronics, Jpn. J. Appl. Phys. 54 (2015) 040102(1-12).

[15] J. Li, L. Li, B. Zhang, M. Yu, H. Ma, J. Zhang, C. Zhang, J. Li, Synthesis of Few-Layer Reduced Graphene Oxide for Lithium-Ion Battery Electrode Materials Ind. Eng. Chem. Res. 53 (2014) 13348-13355.

[16] M. Zhou, H. Bi, T. Lin, X. Lu, D. Wan, F. Huang, J. Lin, Heat transport enhancement of thermal energy storage material using graphene/ceramic composites, Carbon. 75 (2014) 314321.

[17] C. Y. Su, A. Y. Lu, Y. G. Xu, F. R. Chen, A. N. Khlobystov, L. J. Li, High-Quality Thin Graphene Films from Fast Electrochemical Exfoliation, ACS Nano. 5(3) (2011) 2332-2339.

[18] C. M. P. Kumar, T. V. Venkatesha, R. Shabadi, Preparation and corrosion behavior of Ni and Ni-graphene composite coatings, Mater. Res. Bull. 48 (2013) 1477-1483.

[19] M. K. P. Kumar, M. Y. Rekha, J. Agrawal, T. M. Agarwal, C. Srivastava, Microstructure, morphology and electrochemical properties of $\mathrm{ZnFe}-\mathrm{Graphene}$ composite coatings, J. Alloys Compd. 783 (2019) 820-827.

[20] A. A. Javidparvar, R. Naderi, B. Ramezanzadeh, Epoxy-polyamide nanocomposite coating with graphene oxide as cerium nanocontainer generating effective dual active/barrier corrosion protection, Compos. B. Eng. 172 (2019) 363-375. 
[21] N. N. Taheri, B. Ramezanzadeh, M. Mahdavian, Application of layer-by-layer assembled graphene oxide nanosheets/polyaniline/zinc cations for construction of an effective epoxy coating anti-corrosion system, J. Alloys Compd. 800 (2019) 532-549.

[22] N. Parhizkar, T. Shahrabi, B. Ramezanzadeh, Steel surface pre-treated by an advance and eco- friendly cerium oxide nanofilm modified by graphene oxide nanosheets; electrochemical and adhesion measurements, J. Alloys Compd. 747 (2018) 109-123.

[23] N. Parhizkar, B. Ramezanzadeh, T. Shahrabi, Corrosion protection and adhesion properties of the epoxy coating applied on the steel substrate pre-treated by a sol-gel based silane coating filled with amino and isocyanate silane functionalized graphene oxide nanosheets, Appl. Surf. Sci. 439 (2018) 45-59.

[24] S. Asaldoust, B. Ramezanzadeh, Synthesis and characterization of a high-quality nanocontainer based on benzimidazole-zinc phosphate (ZPBIM) tailored graphene oxides; A facile approach to fabricating a smart self-healing anti-corrosion system, J. Collioid Interf. Sci. 564 (2020) 230-244.

[25] A. A. Javidparvar, R. Naderi, B. Ramezanzadeh, L-cysteine reduced/functionalized graphene oxide application as a smart/control release nanocarrier of sustainable cerium ions for epoxy coating anti-corrosion properties improvement, J. Hazard. Mater. 389 (2020) 122135.

[26] M. K. P. Kumar, M. P. Singh, C. Srivastava, Electrochemical behavior of Zn-graphene composite coatings, RSC Adv. 5 (2015) 25603-25608.

[27] V. Kanagalasara, T. V. Venkatesha, Studies on electrodeposition of Zn-MoS 2 nanocomposite coatings on mild steel and its properties, J. Solid State Electrochem. 16 (2012) 993-1001.

[28] L. Alexander, H. P. Klug, Determination of Crystallite Size with the X-Ray Spectrometer, J. Appl. Phys. 21 (1950) 137-142.

[29] M. Mahdavian, M. M. Attar, Another approach in analysis of paint coatings with EIS measurement: Phase angle at high frequencies, Corros. Sci. 48 (2006) 4152-4157.

[30] W. Liu, H. Zhang, Z. Qu, Y. Zhang, J. Li, Corrosion behavior of the steel used as a huge storage tank in seawater, J. Solid State Electrochem. 14 (2010) 965-973.

[31] A. P. Meshram, M. K. P. Kumar, C. Srivastava, Enhancement in the corrosion resistance behaviour of amorphous NieP coatings by incorporation of graphene, Diam. Relat. Mater. 105 (2020) 107795(1-9) 


\section{Figure Captions:}

Fig. 1. (a) Representative $S E M$ micrographs $\mathrm{G}_{0}, \mathrm{G}_{10}, \mathrm{G}_{25}, \mathrm{G}_{50}$ and $\mathrm{G}_{75}$ coatings, (b) Representative SEM micrographs showing partially embedded graphene layers in $\mathrm{G}_{10}, \mathrm{G}_{25}, \mathrm{G}_{50}$ and $\mathrm{G}_{75}$ coatings.

Fig. 2. Cathodic polarization curve recorded from the plating bath $B_{0}$ and $B_{25}$ on the mild steel disc with respect to $1 \mathrm{M} \mathrm{Ag} / \mathrm{AgCl}$ reference electrode.

Fig. 3. X-ray diffraction of $\mathrm{ZnNiFe}$ and $\mathrm{ZnNiFe}-\mathrm{G}$ coatings: (a) for 2-theta value in the range of $35-50$, (b) for 2-theta value in the range of 50-90.

Fig. 4. Tafel polarization curves of the $\mathrm{ZnNiFe}$ and $\mathrm{ZnNiFe}-\mathrm{G}$ coatings in $3.5 \mathrm{wt} \% \mathrm{NaCl}$ media against $1 \mathrm{M} \mathrm{Ag} / \mathrm{AgCl}$ reference electrode.

Fig. 5. Impedance data presented as (A) Nyquist plot (Inset presents the complete Nyquist curve of $\mathrm{G}_{0}$ coating and the capacitive loop present at the high frequency region) (B) Bode plot (log freq. $\mathrm{v} / \mathrm{s} \log |\mathrm{Z}| \&$ phase angle) for the with and without graphene incorporated $\mathrm{ZnNiFe}$ coatings.

Fig. 6. Electrical equivalent circuit (EEC) with $2 \mathrm{RC}$ couple which was used to simulate the EIS data to acquire electrochemical corrosion parameters.

\section{Table Captions:}

\section{Table 1}

Electrolyte composition of the plating bath and operating parameters used deposit with and without Graphene reinforced $\mathrm{ZnNiFe}$ alloy coatings.

\section{Table 2}

Coating composition of the $\mathrm{ZnNiFe}$ and $\mathrm{ZnNiFe}-\mathrm{G}$ coatings obtained from EDS analysis.

\section{Table 3}

Average crystallite size of the different phases ( $\eta \mathrm{Zn}, \gamma \mathrm{Ni}_{2} \mathrm{Zn}_{11}$ and $\mathrm{Fe}$ ) present in the Graphene free and Graphene reinforced $\mathrm{ZnNiFe}$ coatings calculated from Scherrer equation.

\section{Table 4}

Electrochemical corrosion parameters construed from the potentiodynamic polarization curves.

\section{Table 5}

Electrochemical Corrosion parameters obtained from curve fitting the EIS data with 2RC electrical equivalent circuit. 


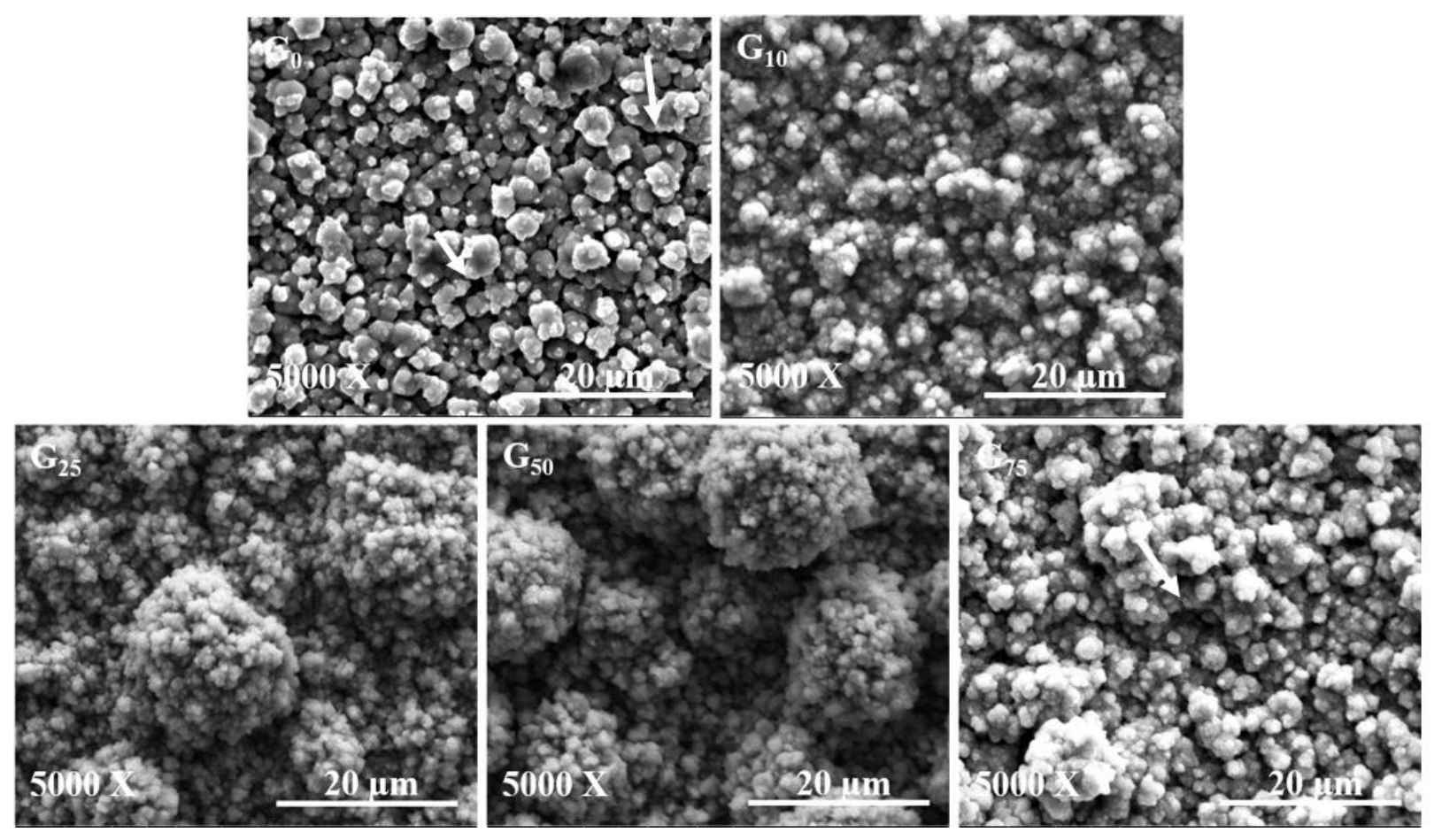

Fig. 1(a) Representative SEM micrographs $\mathrm{G}_{0}, \mathrm{G}_{10}, \mathrm{G}_{25}, \mathrm{G}_{50}$ and $\mathrm{G}_{75}$ coatings 

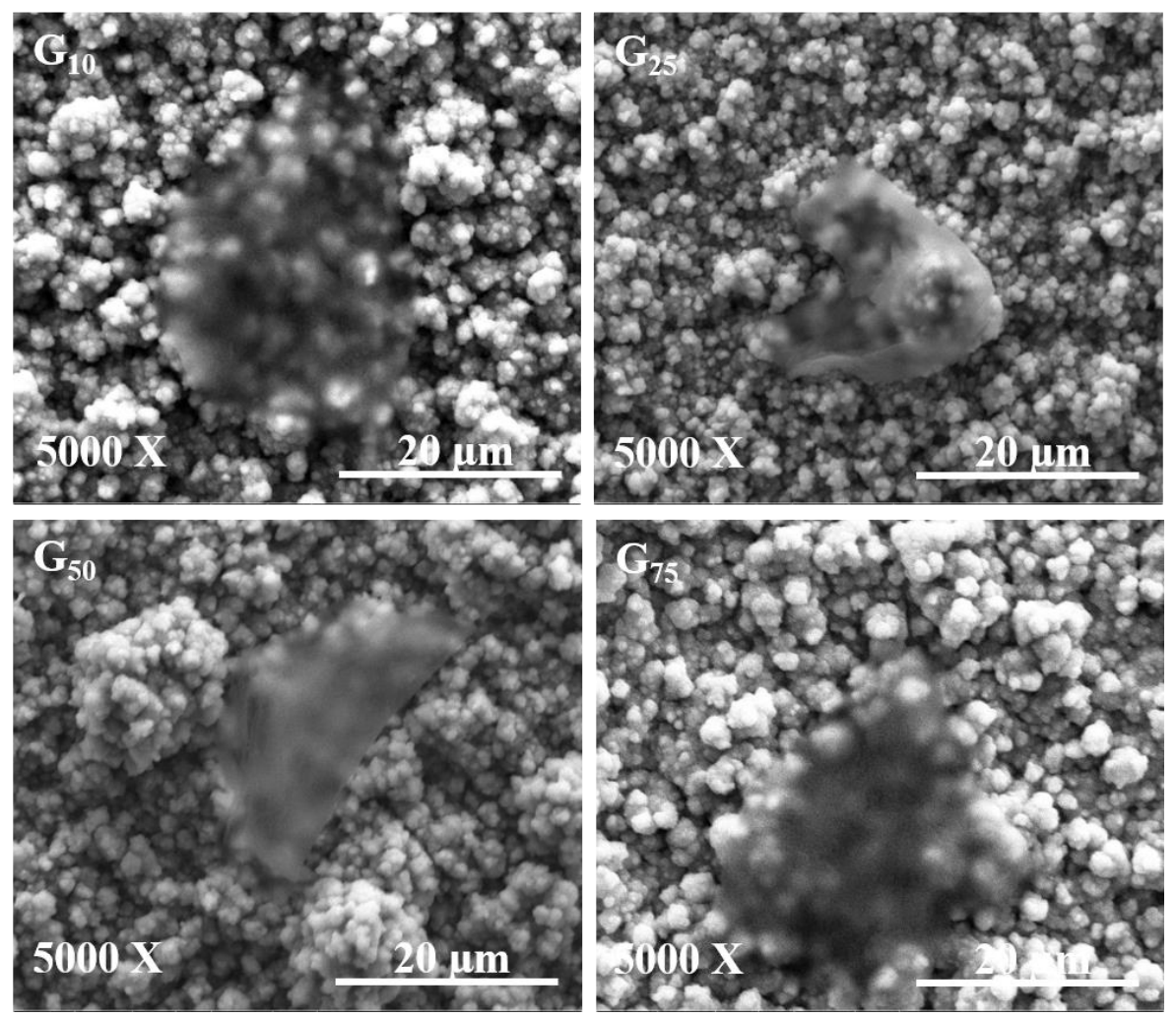

Fig. 1(b) Representative SEM micrographs showing partially embedded graphene layers in $\mathrm{G}_{10}$, $\mathrm{G}_{25}, \mathrm{G}_{50}$ and $\mathrm{G}_{75}$ coatings. 


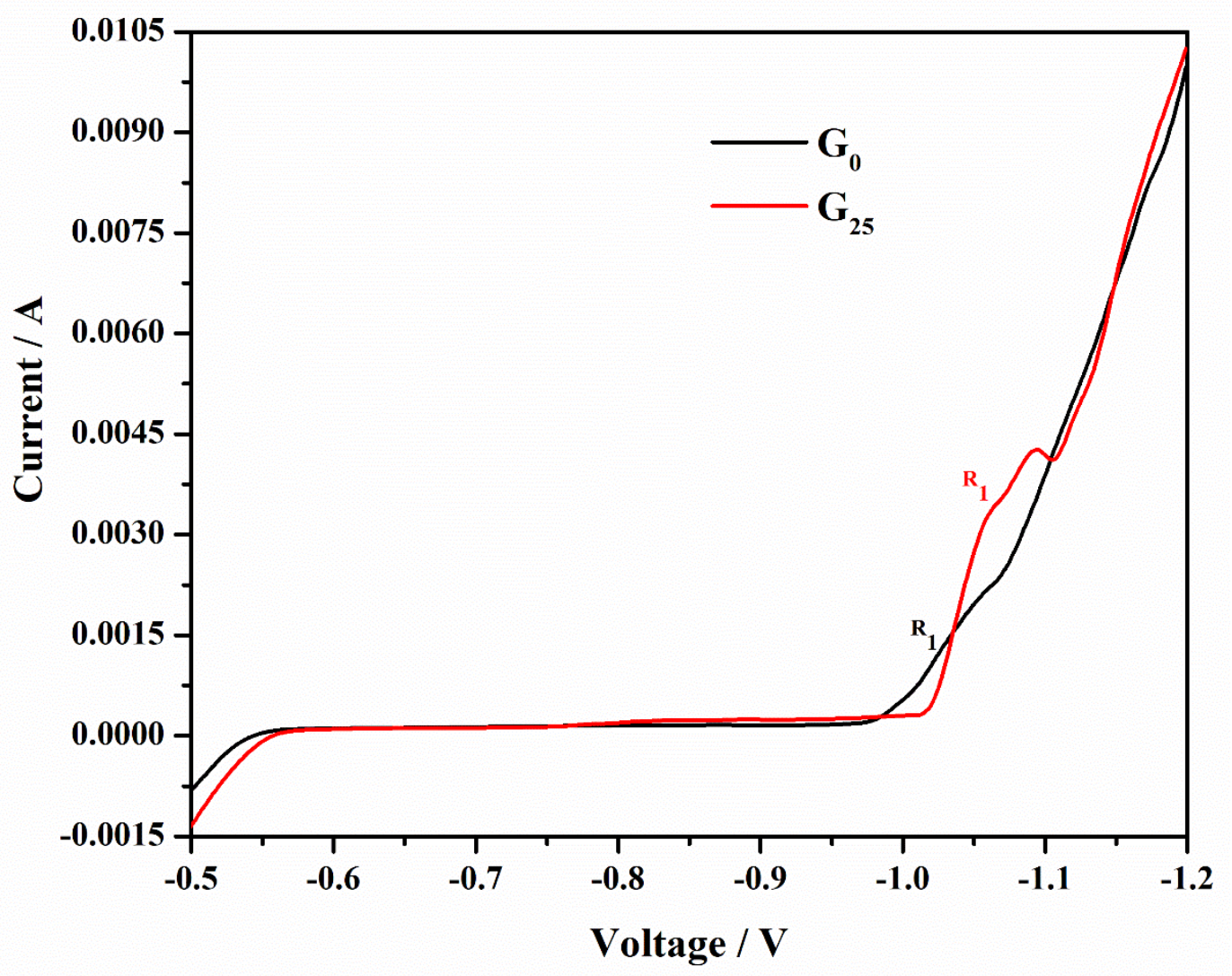

Fig. 2. Cathodic polarization curve recorded from the plating bath $\mathrm{B}_{0}$ and $\mathrm{B}_{25}$ on the mild steel disc with respect to $1 \mathrm{M} \mathrm{Ag} / \mathrm{AgCl}$ reference electrode. 

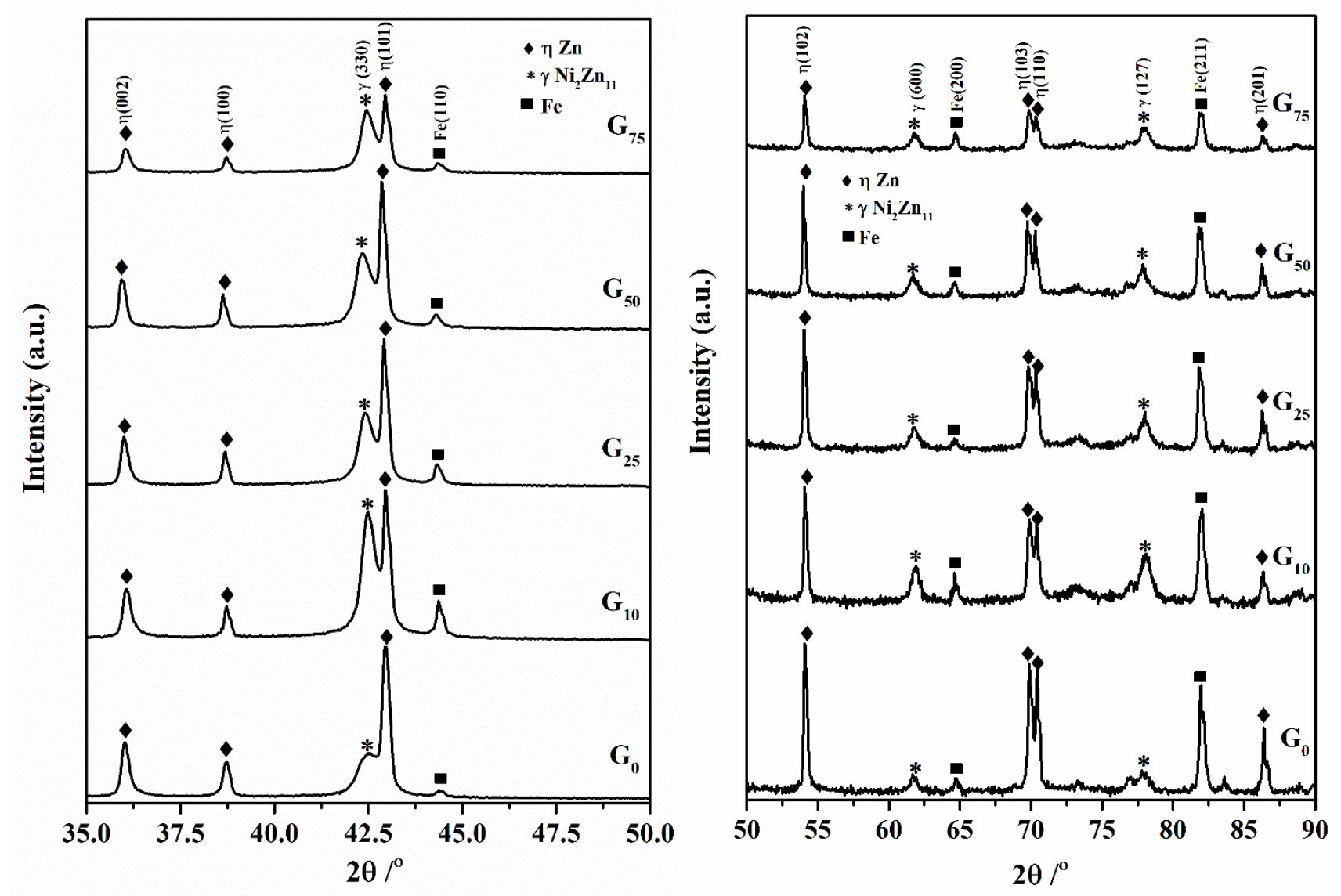

Fig. 3. $\mathrm{X}$-ray diffraction of $\mathrm{ZnNiFe}$ and $\mathrm{ZnNiFe}-\mathrm{G}$ coatings: (a) for 2-theta value in the range of 35-50, (b) for 2-theta value in the range of 50-90. 


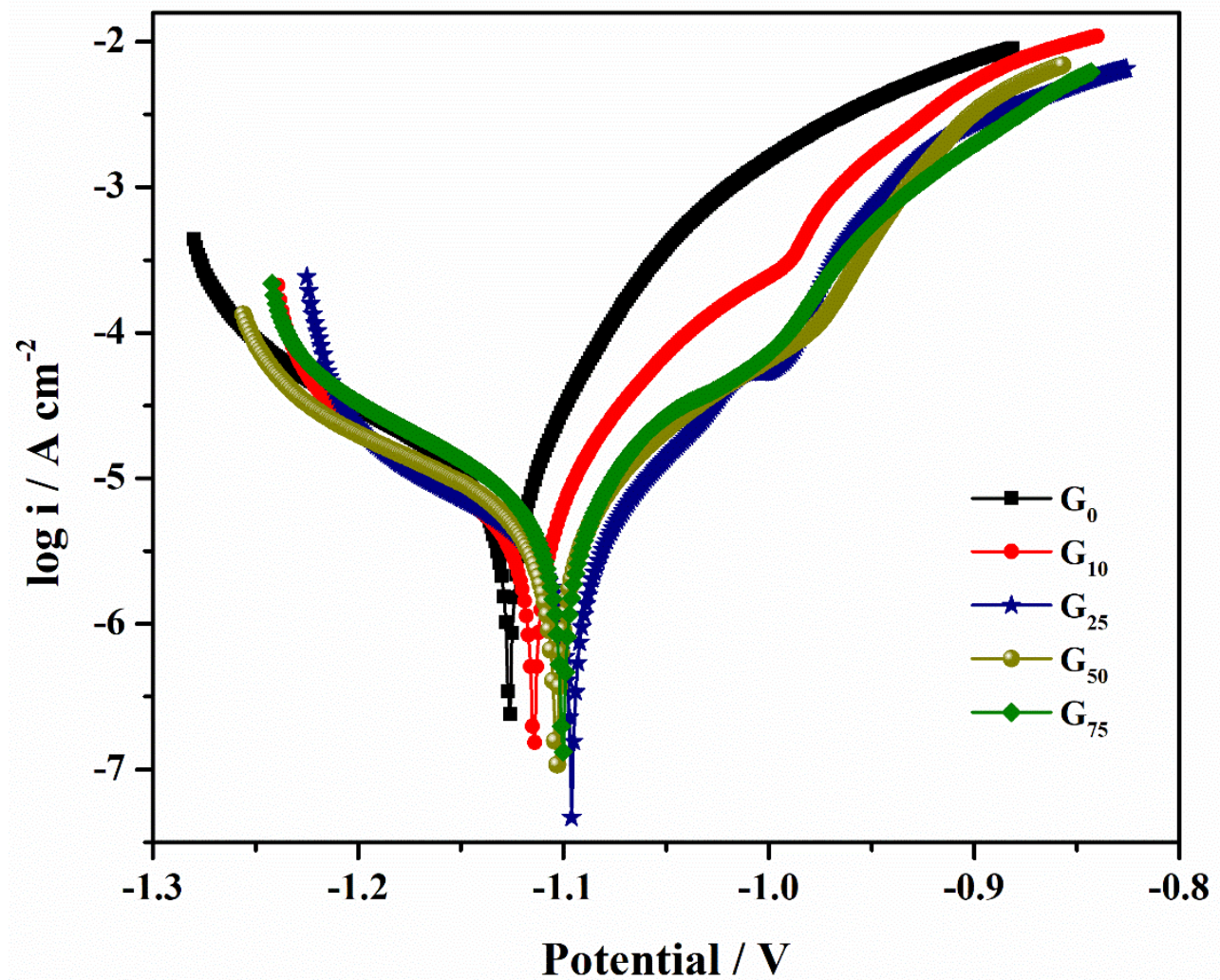

Fig. 4. Tafel polarization curves of the $\mathrm{ZnNiFe}$ and $\mathrm{ZnNiFe}-\mathrm{G}$ coatings in $3.5 \mathrm{wt} \% \mathrm{NaCl}$ media against $1 \mathrm{M} \mathrm{Ag} / \mathrm{AgCl}$ reference electrode. 

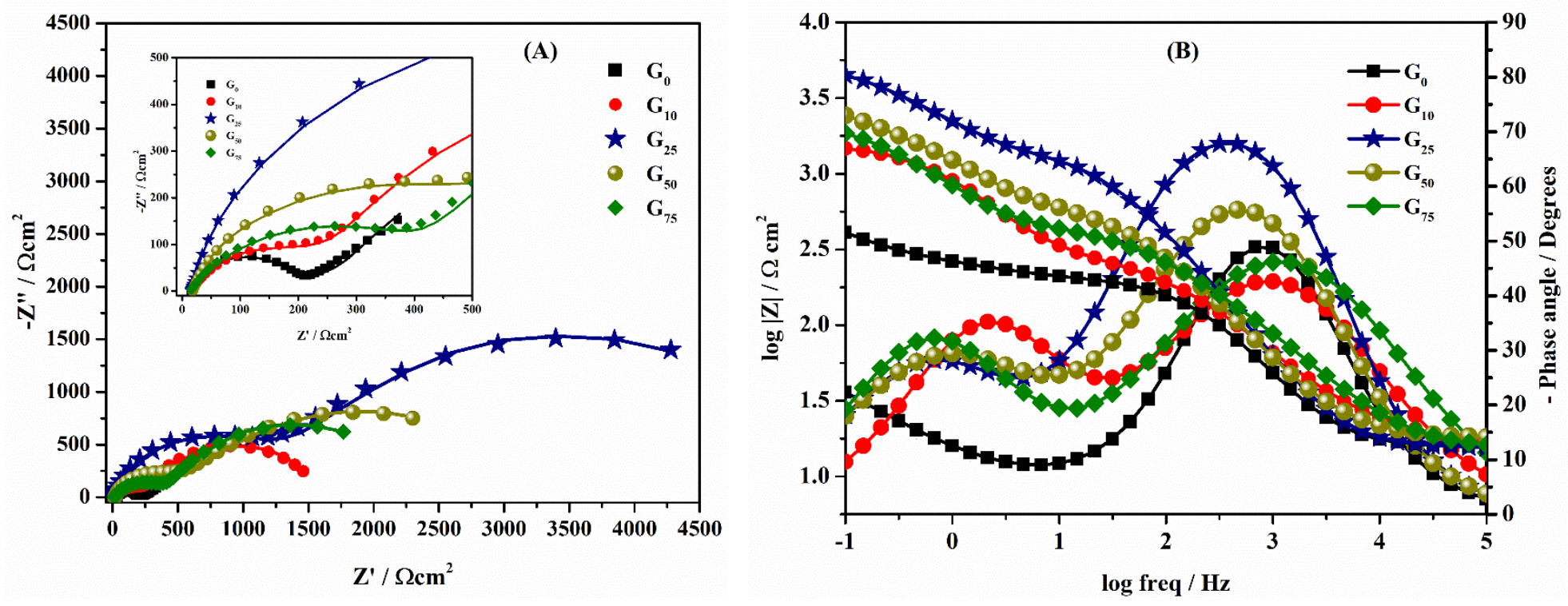

Fig. 5. Impedance data presented as (A) Nyquist plot (Inset presents the complete Nyquist curve of $\mathrm{G}_{0}$ coating and the capacitive loop present at the high frequency region) (B) Bode plot (log freq. $\mathrm{v} / \mathrm{s} \log |\mathrm{Z}| \&$ phase angle) for the with and without graphene incorporated $\mathrm{ZnNiFe}$ coatings. 


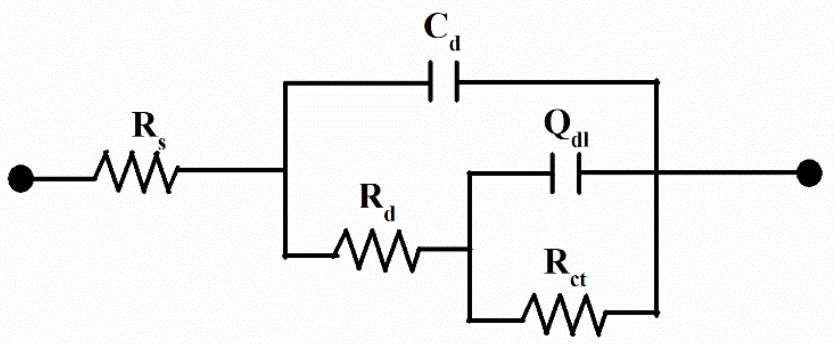

Fig. 6. Electrical equivalent circuit (EEC) with $2 \mathrm{RC}$ couple which was used to simulate the EIS data to acquire electrochemical corrosion parameters. 


\section{Table 1}

Electrolyte composition of the plating bath and operating parameters used deposit with and without Graphene reinforced $\mathrm{Zn}-\mathrm{Ni}-\mathrm{Fe}$ alloy coatings.

\begin{tabular}{ccccc}
\hline Bath & Constituents & Concentration in $\mathrm{g} / \mathrm{l}$ & Deposit code & Operating parameters \\
\hline & $\mathrm{ZnSO}_{4}$ & 160 & & Anode: Platinum plate \\
Basic & $\mathrm{NiSO}_{4}$ & 140 & & Cathode: Mild steel plate \\
Bath & $\mathrm{Fe}_{2} \mathrm{SO}_{4}$ & 150 & $\mathrm{G}_{0}$ & $\begin{array}{c}\text { Current density: } 0.01 \mathrm{~A} \mathrm{~cm}^{-2} \\
\mathrm{Na}_{2} \mathrm{SO}_{4}\end{array}$ \\
$\left.\mathrm{~B}_{0}\right)$ & $\mathrm{H}_{3} \mathrm{BO}_{3}$ & 10 & & Plating time: $45 \mathrm{~min}$ \\
& $\mathrm{CTAB}$ & 0.2 & & pH: 3.2 \\
& & & & \\
\hline $\mathrm{B}_{1}$ & Graphene $+\mathrm{BB}$ & 0.010 & $\mathrm{G}_{10}$ & \\
$\mathrm{~B}_{2}$ & Graphene $+\mathrm{BB}$ & 0.025 & $\mathrm{G}_{25}$ & \\
$\mathrm{~B}_{3}$ & Graphene $+\mathrm{BB}$ & 0.050 & $\mathrm{G}_{50}$ & \\
$\mathrm{~B}_{4}$ & Graphene $+\mathrm{BB}$ & 0.075 & $\mathrm{G}_{75}$ & \\
\hline
\end{tabular}




\section{Table 2}

Coating composition of the $\mathrm{Zn}-\mathrm{Ni}-\mathrm{Fe}$ and $\mathrm{Zn}-\mathrm{Ni}-\mathrm{Fe}-\mathrm{G}$ coatings obtained from EDS analysis.

\begin{tabular}{ccccc}
\hline & C wt\% & Fe wt\% & Ni wt\% & Zn wt\% \\
\hline $\mathbf{G}_{\mathbf{0}}$ & & $1.23 \pm 0.17$ & $3.54 \pm 0.34$ & $95.22 \pm 0.41$ \\
$\mathbf{G}_{10}$ & $2.41 \pm 0.16$ & $2.08 \pm 0.28$ & $4.92 \pm 0.48$ & $90.58 \pm 0.58$ \\
$\mathbf{G}_{\mathbf{2 5}}$ & $3.45 \pm 0.67$ & $2.09 \pm 0.14$ & $6.54 \pm 0.70$ & $88.09 \pm 0.62$ \\
$\mathbf{G}_{50}$ & $2.66 \pm 0.23$ & $2.00 \pm 0.14$ & $6.19 \pm 0.40$ & $89.17 \pm 0.47$ \\
$\mathbf{G}_{\mathbf{1 5}}$ & $2.53 \pm 0.82$ & $2.19 \pm 0.21$ & $5.77 \pm 1.08$ & $89.50 \pm 1.11$ \\
\hline
\end{tabular}




\section{Table 3}

Average crystallite size of the different phases ( $\eta \mathrm{Zn}, \gamma \mathrm{Ni}_{2} \mathrm{Zn}_{11}$ and Fe) present in the Graphene free and Graphene reinforced $\mathrm{Zn}-\mathrm{Ni}-\mathrm{Fe}$ coatings calculated from Scherrer equation.

\begin{tabular}{|c|c|c|c|}
\hline & $\begin{array}{l}\text { Average crystallite } \\
\text { size of } \eta \mathrm{Zn} \text { in } \mathrm{nm}\end{array}$ & $\begin{array}{c}\text { Average crystallite size } \\
\text { of } \gamma \text { Ni2Zn11 in } \mathrm{nm}^{2}\end{array}$ & $\begin{array}{c}\text { Average crystallite } \\
\text { size of Fe phase in } \mathrm{nm}\end{array}$ \\
\hline $\mathbf{G}_{0}$ & 61.1 & 25.1 & 44.6 \\
\hline $\mathbf{G}_{10}$ & 57.6 & 23.1 & 35.1 \\
\hline $\mathbf{G}_{25}$ & 70.0 & 26.9 & 44.2 \\
\hline G50 & 65.6 & 25.2 & 56.2 \\
\hline $\mathbf{G}_{75}$ & 62.3 & 32.7 & 58.1 \\
\hline
\end{tabular}




\section{Table 4}

Electrochemical corrosion parameters construed from the potentiodynamic polarization curves.

\begin{tabular}{cccccc}
\hline Sample & $\mathbf{E}_{\mathbf{c o r r}} \mathbf{V}$ & $\begin{array}{c}\mathbf{I}_{\mathbf{c o r r}} \\
\boldsymbol{\mu} \mathbf{A} / \mathbf{c m}^{\mathbf{2}}\end{array}$ & $\begin{array}{c}\boldsymbol{\beta}_{\mathrm{a}} \\
\mathbf{m V} / \mathbf{d e c}\end{array}$ & $\begin{array}{c}\boldsymbol{\beta}_{\mathbf{c}} \\
\mathbf{m V} / \mathbf{d e c}\end{array}$ & $\begin{array}{c}\mathbf{C R} \\
\boldsymbol{\mu g} / \mathbf{h r}\end{array}$ \\
\hline $\mathbf{G}_{\mathbf{0}}$ & $-1.126 \pm 0.018$ & $9.359 \pm 0.717$ & 46 & 130 & $11.42 \pm 0.938$ \\
$\mathbf{G}_{\mathbf{1 0}}$ & $-1.114 \pm 0.021$ & $4.274 \pm 0.124$ & 41 & 94 & $5.213 \pm 0.151$ \\
$\mathbf{G}_{\mathbf{2 5}}$ & $-1.096 \pm 0.013$ & $2.504 \pm 0.143$ & 50 & 77 & $3.054 \pm 0.175$ \\
$\mathbf{G}_{\mathbf{5 0}}$ & $-1.103 \pm 0.01$ & $3.957 \pm 0.127$ & 57 & 89 & $4.827 \pm 0.177$ \\
$\mathbf{G}_{\mathbf{7 5}}$ & $-1.1 \pm 0.016$ & $4.134 \pm 0.077$ & 49 & 68 & $5.043 \pm 0.09$ \\
\hline
\end{tabular}


Table 5

Electrochemical Corrosion parameters obtained from curve fitting the EIS data with 2RC electrical equivalent circuit.

\begin{tabular}{|c|c|c|c|c|c|c|}
\hline Sample & 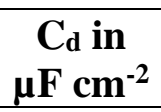 & $\begin{array}{c}R_{d} \text { in } \Omega \\
\mathbf{c m}^{2}\end{array}$ & $\begin{array}{l}Q_{d l} \text { in } 10^{-3} \\
\left(\Omega^{-1} \mathbf{c m}^{-2} S^{-n}\right)\end{array}$ & ndl & $\begin{array}{c}R_{c t} \text { in } \Omega \\
\mathbf{c m}^{2}\end{array}$ & $\begin{array}{l}* \mathbf{R}_{\mathbf{p}} \text { in } \\
\Omega \mathrm{cm}^{2}\end{array}$ \\
\hline $\mathbf{G}_{0}$ & 11.89 & 179 & $5.267 \pm 0.98$ & 0.40 & 202 & $381 \pm 23$ \\
\hline $\mathbf{G}_{10}$ & 33.08 & 292 & $0.220 \pm 0.06$ & 0.79 & 1168 & $1460 \pm 42$ \\
\hline $\mathbf{G}_{25}$ & 7.30 & 1295 & $0.187 \pm 0.03$ & 0.77 & 2982 & $4277 \pm 69$ \\
\hline $\mathbf{G}_{50}$ & 13.59 & 544 & $0.306 \pm 0.07$ & 0.65 & 1755 & $2299 \pm 30$ \\
\hline $\mathbf{G}_{75}$ & 26.77 & 439 & $0.402 \pm 0.08$ & 0.76 & 1329 & $1768 \pm 18$ \\
\hline
\end{tabular}

$* \mathbf{R}_{\mathbf{p}}=\left(\mathbf{R}_{\mathbf{d}}+\mathbf{R}_{\mathbf{c t}}\right)$ 